
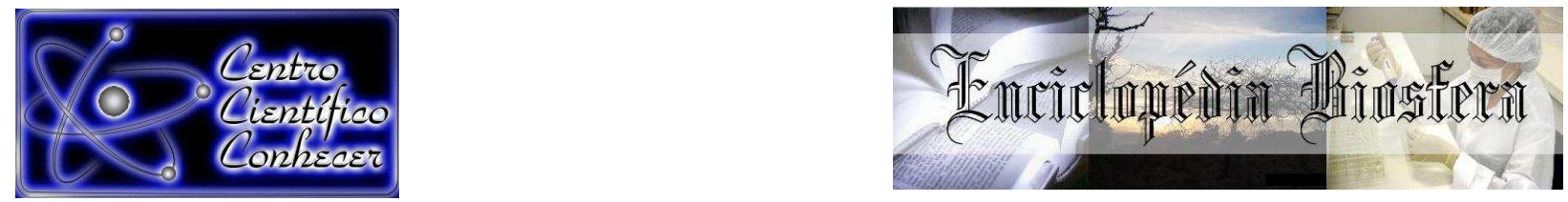

\title{
EDUCAÇÃO AMBIENTAL NAS ESCOLAS DO GOVERNO DO DISTRITO FEDERAL
}

\section{Débora Maria da Silva Freitas ${ }^{1}$, Ivan Rocha ${ }^{2}$}

1. Mestre e Doutoranda da Universidade do Rio Grande do Sul- UFGRS (d.osa@bol.com.br)

2. PhD on Electronics. Docente da UFRGS

Recebido em: 08/09/2015 - Aprovado em: 14/11/2015 - Publicado em: 01/12/2015 DOI: http://dx.doi.org/10.18677/Enciclopedia_Biosfera_2015_053

\begin{abstract}
Esta pesquisa resultou de um trabalho desenvolvido com o propósito de verificar nos Projetos Político-Pedagógicos (PPP) escolares de 2014, a existência de projetos de Educação Ambiental (EA) nas escolas públicas, confrontando-as com a realidade encontrada pela pesquisa da Secretaria de Educação do Distrito Federal (SEDF) sobre a existência de EA nas escolas em 2012. A pesquisa foi de cunho qualitativo e quantitativo. Na coleta de dados utilizou-se a análise documental dos PPP e entrevista semiestruturada com o chefe do Núcleo de Educação Ambiental - NEA da SEDF, a época. Para a análise foi elaborado um roteiro com informações encontradas nos PPP. Com base na análise dos dados pode-se afirmar que as escolas apresentam projetos referentes à EA nos PPP, e são desenvolvidos transversalmente; embora não declarem a participação da comunidade externa à escola. A temática encontra-se diversificada com vários tipos de projetos, e não como os apresentados pela SEDF. Observou-se que, embora os PPP declarem desenvolver trabalhos com a temática ambiental não trazem indicações que permitam identificar fundamentos teóricos e metodológicos para as ações ambientais programadas, e são sugeridas algumas alternativas para reorganização da EA para a SEDF. A partir deste trabalho verificou-se a necessidade de ampliar a pesquisa em projetos escolares para auxiliar a compreensão de como a escola atinge e desenvolve suas propostas de ensino.
\end{abstract}

RESUMO

PALAVRAS-CHAVE: Distrito federal, Educação Ambiental, Projeto PolíticoPedagógico, Distrito Federal.

\section{ENVIRONMENTAL EDUCATIONTHE GOVERNMENT SCHOOLS OF THE FEDERAL DISTRICT}

\begin{abstract}
The purpose of this investigation is to identify the presence of environmental education in the public schools of the Federal District-DF, This research results from work intends to verify in the political-pedagogical projects (PPP) school of 2014, the existence of Environment Education (EE) projects in public schools, confronting with reality found in Secretary of Education of the Federal District (SEDF) of research on the existence of EE in schools in 2012. The research is qualitative and quantitative
\end{abstract}


nature. In the data collection was used the documentary analysis of the PPP and semi-structured interview with the head of the Environmental Education Center - NEA of the Federal District Secretary of Education. A road map was drawn up with information found in PPP. Based on the analysis of the data it can be argued that schools have projects related to EA in PPP, and are developed across; though not declare the participation of the community outside the school. The issue showed diversified with various types of projects, and not with those submitted by the SEDF. It was observed that although the PPP declare develop work on environmental issues, do not provide information identifying theoretical and methodological foundations for the planned environmental actions, and suggests some alternatives for reorganization of EA with the SEDF. From this work there is the need to expand research on school projects to help understanding how the school achieves and develops its educational proposals.

KEYWORDS: Environmental Education; Politico-Pedagógico Project 2. Distrito Federal.

\section{INTRODUÇÃO}

Nos últimos anos, a preocupação com o meio ambiente tem sido muito observada e discutida, pois a humanidade percebeu que, com as agressões que têm feitas ao meio ambiente, os resultados e consequências estão sendo sentidas por ela mesma. Isso ocorre, principalmente, desde que as novas tecnologias começaram a associar doenças e desequilíbrios ecológicos com a ação humana (FREITAS, 2010).

Com a necessidade de um enfrentamento mais eficaz dessas alterações ambientais e dos efeitos sobre a saúde humana, a Educação Ambiental - EA surge como alternativa para influir nas atitudes humanas em relação ao meio ambiente. $\mathrm{Na}$ prática necessita ainda de muitos avanços, para que realmente se tenha uma ação transformadora (DACACHE, 2004). Umas das alternativas encontradas para contribuir com a solução desta questão é a inclusão da Educação Ambiental no ensino formal.

O processo de institucionalização da Educação Ambiental no Brasil teve seu início na década de 70, com a criação da Secretaria Especial do Meio Ambiente SEMA, subordinada diretamente a Presidência da República - PR (BRASIL 2005). $\mathrm{Na}$ década de 90 teve início a consolidação da $E A$, com os movimentos ambientalistas que passam a ter maior proeminência na vida social brasileira. Os indivíduos se tornaram mais sensibilizados para com a problemática ambiental, e iniciou-se um avanço significativo no processo de conscientização popular (DIAS, 2000).

As ações educativas ambientais vêm se destacando frente à crise socioambiental decorrente das ações humanas, onde muitas escolas adotaram a EA nos debates na Rio-92, a conferência sobre o meio ambiente e desenvolvimento promovido pela ONU no Rio de Janeiro em 1992 (TRAJBER, 2007). Neste cenário o Brasil oficializou um plano nacional de EA, a Política Nacional de Educação Ambiental - PNEA, instituída pela Lei 9.795/1999, como também, um Programa Nacional de Educação Ambiental (ProNEA) que estabeleceu, princípios, diretrizes, e estratégias gerais para a efetivação da EA no país, bem como as questões ambientais formais. No âmbito escolar, estão definidas na Lei de Diretrizes e Bases (LDB), nos Parâmetros Curriculares Nacionais (PCN) e os Temas Transversais (BRASIL, 1997 e 2005). 
Neste contexto é que se pretende desenvolver a atual pesquisa, verificar a inserção da EA nas escolas do DF, investigando os PPP e confronta-los com a pesquisa realizada em 2012 pela SEDF sobre a presença da EA nas escolas do DF. Na visão de VEIGA (1995) e HERNÁNDEZ (1998) uma forma de instituir o ensino da EA nas escolas é inseri-la por meio de projetos pedagógicos, de forma continuada e abrangente. Ao facilitar 0 processo de aprendizagem, os projetos podem proporcionar a vivência das situações relativas ao meio ambiente, mesmo fora das salas de aula.

\section{MATERIAL E MÉTODOS}

As informações sobre as propostas e atividades de EA contidas nos Projetos Político-Pedagógicos (PPP) das escolas públicas de ensino básico do DF foram analisadas de forma qualitativa e quantitativa. Para análise foi utilizado o PPP de 2014.

O Distrito Federal possui 664 instituições de ensino (urbanas e rurais), com 470.838 alunos matriculados, de acordo com dados da Secretaria de Educação (http://www.se.df.gov.br), que se encontram distribuídos pelas 31 regiões administrativas, estando agrupadas em 14 Coordenações Regionais de Ensino (CRE) autônomas.

A amostra para esta pesquisa é considerada não probabilística (GIL, 1987), onde "o pesquisador seleciona os elementos a que tem acesso, admitindo que estes possam de alguma forma representar o universo". A proposta foi trabalhar com um número de 4 (quatro) unidades escolares por Coordenação Regional de Ensino CRE, dividida em: 2 (duas) escolas de ensino fundamental e 2 (duas) escolas de ensino médio. As CRE foram selecionadas em função do número de habitantes (Dados da Companhia de Planejamento do DF - CODEPLAN) e do maior número de escolas por região. Desta forma a pesquisa abrangeu sete das $14 \mathrm{CRE}$, entre estas - Plano Piloto, totalizando 28 escolas selecionadas, o número de alunos matriculados, pelos dados do censo da SEDF de 2014, é de 136.809 alunos no ensino fundamental (anos finais) e 80.832 alunos no ensino médio, totalizando 548 escolas para os dois níveis de ensino (Sítio da SEDF).

Seguindo as informações do Censo Escolar de 2004, o Ministério da Educação - MEC, em 2006, encomendou a pesquisa "O QUE FAZEM AS ESCOLAS QUE DIZEM QUE FAZEM EDUCAÇÃO AMBIENTAL", com o objetivo de ampliar o conhecimento sobre as práticas de EA realizadas pelas escolas brasileiras, públicas e privadas de ensino fundamental (BRASIL, 2006).

Os dados foram obtidos por meio de um questionário com 20 perguntas de múltipla escolha, realizada pela SEDF entre os meses de março e agosto do ano de 2012, o qual foi concedido na realização da entrevista com o chefe do Núcleo de Educação Ambiental - NEA em 26 de fevereiro de 2014 e a análise das orientações e dos Projetos Políticos Pedagógicos - PPP para o ano de 2014 das escolas selecionadas da SEDF. A coleta de dados ocorreu entre os anos de 2014 e início de 2015.

A coleta dos dados foi realizada em duas etapas: a primeira constituiu-se de uma entrevista semiestruturada com o chefe do Núcleo de Educação Ambiental NEA/SEDF, onde foi concedida a síntese (diagnóstico) da pesquisa realizada pela SEDF quanto à presença da EA nas escolas da rede pública de ensino do DF, no ano de 2012.

A entrevista é considerada por LUDKE \& ANDRÉ (1986), como uma importante ferramenta para a coleta de dados, permite uma maior interação entre os 
interlocutores (entrevistado e entrevistador). Os autores ainda ressaltam que as entrevistas semiestruturadas se desenrolam com maior facilidade, por parte de um esquema básico flexível, que permite ao entrevistador fazer as adaptações necessárias; na segunda, foi feito um levantamento dos documentos de PPP das escolas selecionadas, os quais estão disponibilizados no sítio da SEDF. Na análise destes documentos foi verificada a presença da EA por meio de projetos propostos pela escola no referido documento.

A análise documental é considerada pelos autores LUDKE \& ANDRÉ (1986) como uma fonte de dados rica e estável, pois é onde podem ser encontradas as evidências que fundamentam as informações e declarações do pesquisador e que persistem ao longo dos tempos, podendo ser consultadas várias vezes. Os mesmos autores enumeram algumas vantagens do uso dessa técnica: estabilidade, riqueza da fonte, complementação a outras técnicas e a ausências de alterações de comportamento entre o contato com os sujeitos da pesquisa.

A presença da Educação Ambiental nas escolas do Distrito Federal foi analisada em ocorrência e relações. Embora os dados apresentados sejam quantitativos, o tratamento que tiveram foi qualitativo, pois foi realizada a comparação do que foi proposto em 2012 com o PPP escolar no ano de 2014, quanto à presença da EA nas escolas.

Primeiramente foi relatada a entrevista com o Chefe do Núcleo de Educação Ambiental juntamente com resultado do diagnóstico encontrado em 2012, e disponibilizado para a elaboração deste artigo. Uma vez selecionadas as escolas, os Projetos Político-Pedagógicos de cada unidade foi analisado, utilizando-se os documentos/exemplares disponíveis no sítio da SEDF, que estão em: http://sumtec.se.df.gov.br/sistemas/ppp/

Para a análise dos PPP e com a finalidade de facilitar e organizar as possíveis informações sobre a temática ambiental nos referidos documentos, foi elaborado um roteiro para as anotações, o qual foi estruturado em torno dos seguintes critérios: existência de projetos que se referem à EA; temas desenvolvidos e orientados pela SEDF; envolvimento com a comunidade; conteúdos ou atividades da proposta pedagógica voltada para EA; fundamentação ou referencial teórico que alicerçam a proposta de EA; caráter disciplinar, e comentários em geral.

A partir dessa organização foram feitas as análises, tomando-se como referência os documentos legais, os temas sugeridos pela SEDF e os autores que embasam o presente estudo.

\section{RESULTADOS E DISCUSSÃO}

Com base na análise dos dados pode-se afirmar que as escolas apresentam projetos referentes a EA nos PPP, e são desenvolvidos transversalmente; embora não declarem a participação da comunidade externa à escola. A temática encontrase diversificada com vários tipos de projetos, e não como os apresentados pela SEDF. Observou-se que, embora os PPP declarem desenvolver trabalhos com a temática ambiental não trazem indicações que permitam identificar fundamentos teóricos e metodológicos para as ações ambientais programadas. Foram sugeridas algumas alternativas para reorganização da EA junto a SEDF. A partir deste trabalho verificou-se a necessidade de ampliar a pesquisa em projetos escolares para auxiliar a compreensão de como a escola atinge e desenvolve suas propostas de ensino no DF. 
Em 2013 a Secretaria de Educação contava com 653 unidades escolares, distribuídas pelas cidades satélites do DF, e estão distribuídas por 14 Coordenações Regionais de Ensino. O efetivo contava com cerca de 30 mil professores ativos, 13 mil servidores de carreira e cerca de 500 mil alunos em todas as modalidades de ensino. Dos questionários enviados as escolas, obteve-se o retorno de apenas $50 \%$, ou seja, apenas 327 unidades responderam sobre a prática da Educação Ambiental formal.

Cerca de 200 unidades (60\%) afirmaram que tinham ou tiveram projetos de educação ambiental, e destes, $75 \%$ afirmavam que ainda possuíam com esta finalidade. Os temas mais presentes nos projetos foram: $36 \%$ na área de Gestão de Resíduos (coleta seletiva); 30\% na área de Hortas escolares; $7 \%$ em Educação Patrimonial e 3\% na área de Diminuição no Consumo de Recursos Naturais. A presença destes temas evidencia uma EA mais naturalista e restrita (GRUN, 1996), o que LIMA (2002) também classifica como uma educação voltada à conservação do ambiente e conservadora, e não uma EA com visão crítica e de conscientização.

Quando perguntados quais os componentes curriculares estavam envolvidos nas ações de EA, os conteúdos que mais tiveram destaque foram: com $56 \%$ Língua Portuguesa; 49\% Matemática; 47\% Atividades; 43\% Geografia; 37\% Arte (Educação Artística); 24\% em Historia; 18\% com as praticas de Educação Física e apenas 16\% em Biologia. Desta forma observa-se a dificuldade, que segundo OLIVEIRA (2000), das questões ambientais tem de se tornar conteúdos multidisciplinares, pois aparentemente a EA está presente nas varias disciplinas, mas de forma fragmentada.

Sobre a comunidade escolar participante ou envolvida com os projetos/ ações de EA, quais eram os atores que tinham uma participação direta com os projetos: 94\% Direção; 70\% Servidores (limpeza e cozinha); 56\% Pais, Mães e/ou Responsáveis; $52 \%$ Orientador Educacional; 43\% Sala de Recursos; 33\% Secretaria Escolar.

Para o desenvolvimento das atividades dos projetos de EA são usados os seguintes espaços: $86 \%$ espaços internos da escola, fora da sala de aula; $74 \%$ na sala de Aula; $46 \%$ nos espaços externos à escola. Estes dados confirmam o pensamento de VEIGA (2003), que a escola é o principal local de desenvolvimento da consciência critica da realidade. Ao serem perguntadas se haviam pedido ajuda a SEDF para desenvolvê-los, sobre o desenvolvimento dos projetos de EA, responderam positivamente e os pedidos foram referentes à: $41,5 \%$ Capacitação/Formação Continuada; 41\% Apoio Financeiro e Técnico; 33\% Material Didático e Equipamentos.

Após o levantamento e a construção do novo cenário, a ideia era ter a implementação de uma política de educação ambiental no perfil desejado pela SEDF, conectando atores e propondo um trabalho compartilhado, complementar e contínuo; a formulação e ampla divulgação de diretrizes e orientações pedagógicas para trabalhar com programas estabelecidos pelo NEA/SEDF (as hortas escolares, consumo consciente, prevenção à dengue, bioma cerrado), esperando que se tivessem mais escolas sustentáveis e preparadas para um novo modelo de sociedade.

Para viabilizar a implementação dessa política a SEDF conta com a ajuda da implantação de alguns instrumentos como: a Comissão de Meio Ambiente e Qualidade de Vida na Escola; Agenda 21 escolar e projetos de Escolas 
Sustentáveis, como também com a implantação destas ações com a construção dos PPP.

Segundo HERNÀNDEZ (1998) a construção/elaboração do PPP engloba além de esforços, as relações dentro do contexto escolar (trabalho pedagógico, administrativo, financeiro e da comunidade escolar). Com este trabalho de construção/elaboração do PPP é possível atender ideais e anseios da comunidade escolar, e, ainda, permitir que a escola faça as escolhas a respeito da melhor maneira de educar e exercer a autonomia.

A elaboração do Projeto Político-Pedagógico das escolas da SEDF é orientada pela Subsecretaria de Educação Básica-SUBEB e Coordenações Regionais de Ensino/Gerências de Educação Básica-CRE/GEB por meio da Orientação Pedagógica Projeto Político Pedagógico e Coordenação Pedagógica, dando autonomia às escolas para a construção do PPP.

A autonomia é delegada as escolas públicas, que segundo VEIGA (2003), promove a esta a capacidade de delinear a própria identidade, o PPP deve ser elaborado dentro da escola, com a participação da comunidade escolar (professores, equipe pedagógica), respeitando a realidade de cada unidade e do tipo de aluno, considerando os currículos em movimento e os temas contemporâneos, chamados eixos transversais.

Em linhas gerais as orientações estabelecem que os PPP das escolas do Distrito Federal tenham um enfoque humanista, conforme BARROSO (1999), ou seja, holístico (Integração e interação entre todos os elementos que compõem o universo), sistêmico, democrático e participativo, onde se tenha um entendimento do indivíduo como ser humano em toda sua complexidade e integralidade. O processo ensino aprendizagem deve sempre ter foco na interdisciplinaridade com características de continuidades e cíclicas (MOTA, 2012).

Essa orientação é uma contribuição para que o PPP seja construído coletivamente, fomentando as propostas que são diversas pela especificidade de cada escola. Espera-se que assim o processo seja realizado com ampla participação dos profissionais de educação, estudantes, equipes pedagógicas e gestoras, pais, mães, responsáveis e conselhos escolares na tomada de decisões, na definição dos rumos da escola (SEDF, 2008).

Está previsto que sejam abordados alguns tópicos no PPP das escolas: diagnóstico da escola e de seu território; concepções que fundamentam as práticas pedagógicas e administrativas na escola; discussão e elaboração do Plano de Ação. No tocante a Educação Ambiental foi encontrada nas orientações para o PPP das escolas uma única vez quando se trata da "Estrutura do Projeto Politico-Pedagógico, que em seu item 'L",

Organização Curricular da Escola. Com base no Currículo da Educação Básica da SEEDF 2014, cada escola deve apresentar a forma como promove a interdisciplinaridade, o trabalho com projetos, a relação da teoria com a prática, a contextualização, o trabalho com os temas transversais: Educação para a Diversidade; Cidadania e Educação em e para os Direitos Humanos; Educação para a Sustentabilidade. Desenvolvimento de programas e projetos específicos (Centros de Iniciação Desportiva, Educação com Movimento, Programa Saúde na Escola, entre outros) (GDF, 2014).

Ao se analisar o PPP das 28 escolas selecionadas e diante do que foi observado, foi possível tecer uma síntese sobre esses PPP construídos para as ENCICLOPÉDIA BIOSFERA, Centro Científico Conhecer - Goiânia, v.11 n.22; p.3407 
escolas do ensino fundamental e médio das escolas públicas do DF no que se refere a contemplarem projetos de EA em suas atividades ou ações.

Das 28 escolas apenas seis, $21 \%$ das escolas não possuem qualquer indicação a projetos voltados á temática ambiental nos seus PPP, nem mesmo fazem referências a passeios e visitas, ou mesmo sobre comemorações a datas festivas, onde pudessem estar inseridas aquelas orientadas ao meio ambiente, assim como, por exemplo, o Dia do Meio Ambiente e o Dia da Árvore. Com este número pode perceber que esta em conformidade como o diagnóstico de 2012.

No que se refere ao caráter disciplinar todas as escolas que possuem projetos em EA, planejam no PPP caráter transversal e interdisciplinar, embora na descrição dos projetos, apenas são explicados como estes serão realizados com os alunos ou a comunidade (quando há participação), sem delinear o enforque que cada disciplina terá, e pelo relatado no PPP, confirma-se a pretensão da SEDF em 2012, mas deixa a desejar quanto à prática.

Nas referências o que se permite identificar quanto aos fundamentos teóricos para as atividades planejadas, inexiste qualquer referência direta a temática ambiental. Apenas são citados referencias como os PCN e os Temas Transversais de forma geral, a Lei de Diretrizes Básicas - LDB e os Currículos em Movimento com eixos transversais, o que deixa claro a distância entre a teoria e a prática dentro das escolas e as orientações da SEDF. Esta falta de orientação não era a idealizada pela SEDF, quando do cenário encontrado no diagnóstico de 2012.

O envolvimento da comunidade escolar na construção e execução dos PPP pode ser observado no teor dos documentos analisados $(100 \%)$, onde ainda se propõe a questão de uma gestão democrática com o cumprimento de seus princípios. Quanto aos projetos desenvolvidos pelas escolas e identificados através dos PPP, foi encontrado um total de 311 projetos nas diferentes áreas, onde os voltados para a temática ambiental foram 64 encontrados, ou seja, apenas $21 \%$ dos projetos desenvolvidos, pelas escolas pesquisadas, estão relacionados diretamente a questão ambiental, embora a maioria deles não defina os resultados esperados.

Os temas propostos nestes 64 projetos para a questão ambiental estão assim contemplados: 26,56\% Semana de Educação para a Vida; 18,75\% Horta e Alimentação Saudável; 14,06\% Meio Ambiente de forma geral; 12,50\% Feiras de Ciências; $10,93 \%$ Bioma Cerrado e 9,3\% sem referências. Observa-se que os programas propostos pelo NEA/SEDF, não estão sendo acatados para 0 desenvolvimento das práticas de EA nas escolas. O que continua uma educação ambiental com evidencias: naturalista, restritiva e conservadora, segundo a visão dos autores GRUN (1996) e LIMA (2002). Como atividades com propostas pedagógicas voltadas para EA foram encontradas: a participação nas feiras de ciências, passeios a parques e zoológicos e atividades em algumas datas comemorativas.

Outra questão referente à prática das atividades desenvolvidas pelas escolas é que na maioria das vezes elas são realizadas dentro das escolas, ou seja, em salas de aula, laboratórios ou no pátio, o que significa que a execução dos projetos na área ambiental não envolve a comunidade do entorno. O que contraria a visão de FREIRE (1996), que diz que essas atividades educacionais devem ser decorrentes de situações e temas sociais vividas pelos alunos (comunidade do entorno), como o objetivo de analisar os problemas lidados a realidade do próprio aluno. Dessa forma, tanto educador quanto educando passam a fazer parte de um mesmo contexto, e assim passam a aprender continuamente e globalmente. 
Pelo observado no panorama construído a partir das propostas de Educação Ambiental presentes nos PPP das escolas públicas do Distrito Federal e, ainda, pela entrevista e diagnóstico do NEA/SEDF, nos leva a afirmar que é preciso construir coletivamente uma rede de Educação Ambiental, com um envolvimento mais efetivo e maior articulação entre as CRE, o NEA/SEDF e as instituições de ensino.

Sendo essencial que, além da rede, sejam construídas diretrizes de Educação Ambiental que sirvam de guia orientador, e ao mesmo se continue respeitando e valorizando a autonomia e a dinâmica de cada unidade, onde o PPP deverá ser construído de modo a aliar teoria e prática, e o trabalho pedagógico deverá ser desenvolvido com atividades e ações planejadas com a participação da comunidade, favorecendo a ampla discussão sobre os problemas ambientais tanto em nível local como global.

Enfim, constatou-se que a SEDF apresenta boas intenções para a prática e desenvolvimento de ações voltadas à temática ambiental, faltando algumas orientações ou reorganização dessas ações e propostas. Neste sentido, ao tentar colaborar com as prioridades para elaboração de políticas públicas recomenda-se algumas alternativas:

Conhecer as diversidades: as diversidades devem ser reconhecidas, fortalecidas e usadas como inspiração nas instituições escolares ainda sem EA em sua estrutura, mas com o cuidado de não priorizar a padronização das ações na área ambiental, pois teria a vantagem de respeitar a autonomia das escolas de ensinos fundamental e médio no seu planejamento curricular e pedagógico.

- $\quad$ Alterar estruturas: alterar espaços com o objetivo de criar espaços ou estruturas educativas, tais como núcleos ou centros de EA nas escolas, com a finalidade de um espaço de interlocução e de formação para a socialização de saberes e de práticas pedagógicas, visando incorporar a dimensão ambiental na prática de ensino e pesquisas, que venham a funcionar como pontos de sistematização e divulgação de inciativas das atividades escolares, assim como espaços que favoreçam as relações interdisciplinares e transdisciplinares.

- Investir em EA: Investimento são importantes principalmente na formação ambiental de pessoal, como ainda na infraestrutura, instrumentos e procedimentos institucionais de apoio, com a finalidade de transformar a EA em uma dimensão essencial e primordial a todos os níveis da educação.

\section{CONCLUSÃO}

Em comparação ao que foi relatado na entrevista e a percepção da Educação Ambiental analisado no PPP das escolas selecionadas pode se concluir que, embora 22 escolas $-78,57 \%$, das 28 selecionadas, declararem em seus PPP possuir ações ou atividades intituladas como Educação Ambiental, aparentemente não contrariavam as afirmações quanto à presença de EA no meio escolar, revelada no diagnóstico em 2012, mas o panorama encontrado revelou-se diversificado no que se refere às várias práticas de EA dentro das escolas e as estabelecidas pelo NEA/SEDF.

Com essa observação identifica-se uma grande fragilidade, permitida pela pesquisa, a falta de articulação entre as ações planejadas no PPP e o que é proposto pela Secretaria de Educação (NEA), desta maneira percebe-se a falta de um Programa de Educação Ambiental de forma contínua e sistematizada.

Em outras palavras, apesar da Lei no 9.795/99, que instituiu a Política Nacional de EA (PNEA) ter sido regulamentada em 2002 (Decreto n 4.281/2002), o 
levantamento comprovou que, 12 anos depois, ainda são raras as escolas que entendem a EA como dimensão essencial em seus PPP, pois pelo observado não há uma orientação fundamentada pela SEDF e nem pelas escolas, que informam ter EA em suas atividades e ações. Pôde se constatar isto com a análise das fundamentações ou referenciais teóricos, os quais não abordam em momento algum qualquer tipo de referências diretas às questões ambientais.

$E$ ainda observa-se que a EA oferecida, através dos temas propostos pela SEDF, às escolas do DF é de forma naturalista, conservadora e restrita, o que não oferece uma EA conforme a designada pelas diversas conferências mundiais (Belgrado, Tbilisi, entre outras), que deve desenvolver um cidadão consciente do ambiente total, preocupado com os problemas associados a este ambiente e que tenha conhecimento, atitudes, motivações, envolvimento e habilidades para trabalhar individual e coletivamente para resolver problemas atuais e prevenir os futuros.

A partir deste trabalho verificou-se a necessidade de ampliar a pesquisa em projetos escolares para auxiliar a compreensão de como a escola atinge e desenvolve suas propostas de ensino.

\section{REFERENCIAS}

BARROSO, L. R. Interpretação e aplicação da constituição: fundamentos de uma dogmática constitucional transformadora. 3 ed. São Paulo: Saraiva, 1999.

BRASIL. Parâmetros Curriculares Nacionais: Meio Ambiente e saúde MEC/Brasília, 1997.

Educação na diversidade: o que fazem as escolas que dizem que fazem Educação Ambiental/Organização: Rachel Trajber, Patrícia Ramos Mendonça. - Brasília: Secretaria de Educação Continuada, alfabetização e Diversidade, 2006. 256 p.: il - (Coleção Educação para Todos, Série Avaliação; n. 6, v. 23).

Programa Nacional de Meio Ambiente - PRONEA. Ministério do Meio Ambiente, Diretoria de Educação Ambiental; Ministério da Educação. Coordenação Geral de Educação Ambiental. - 3. ed - Brasília : Ministério do Meio Ambiente, 2005.

DACACHE, F. M. Docente da UFF: Uma proposta de educação ambiental utilizando o lixo como um tema interdisciplinar. 2004. 7f. Dissertação (Mestrado em ciência ambiental)-Faculdade de Educação, Universidade Federal Fluminense, Niterói, 2004.

DIAS, G. F. Educação Ambiental: princípios e práticas. São Paulo: GAIA, 2000.

FREITAS, D.M.S.F. Diagnostico e proposta de modelo de gestão de resíduos eletroeletrônico gerados nos ministérios do governo brasileiro. Dissertação (Mestrado). Universidade Católica de Brasília - UCB, Brasília - DF, julho de 2010.

FREIRE, P. Pedagogia da autonomia. Saberes necessários a prática educativa. São Paulo: Paz e Terra, 1996. 
GDF - Governo do Distrito Federal. Secretaria de Estado de Educação Orientações Pedagógicas da SEDF, 2014, Brasília, DF, novembro de 2014.

GIL, A. C. Como elaborar projetos de pesquisa. São Paulo: Atlas, 1987.

GRUN, M. Ética e educação ambiental: a conexão necessária. São Paulo: Papirus, 1996.

HERNÁNDEZ, F., VENTURA, M. A. Organização do currículo por projetos de trabalho - O conhecimento é um caleidoscópio. 5 Ed. Porto Alegre: Artes Médicas, 1998.

LIMA, G. F.C. Crise ambiental, educação e cidadania: os desafios da sustentabilidade emancipatória. IN: LOUREIRO, C.F.B; LAYRARGUES, P.P; CASTRO, R.S. (Org.) Educação ambiental : repensando o espaço da cidadania. São Paulo: Cortez, 2002.

LÜDKE, M.; ANDRÉ, E.D.A. Pesquisa em Educação: Abordagens Qualitativas. São Paulo: Editora Pedagógica e Universitária Ltda, 1986.

MOTA, C., Projeto Politico- Pedagógico - Secretaria de Estado de Educação SEDF-GDF Subsecretaria de Educação Básica, Brasília, 2012.

OLIVEIRA, E. M. Educação Ambiental, uma possível abordagem. 3aa ed. Brasília: Ed. IBAMA, 2000.

SEDF. Dados divulgados pela SEDF em 29/08/2014 - Censo escolar 2014. Total de turmas e matriculas por etapa/modalidade de ensino. Disponível em: http://www.cre.se.df.gov.br/ascom/documentos/censo/2014/turmas_matr\%C3\%ADcu las_2014.pdf

- Orientações Pedagógicas da Secretaria de Estado da Educação do Distrito Federal. In: Diretrizes Pedagógicas da Secretaria de Estado de Educação. Brasília - DF, 2008

TRAJBER, R. (Orgs.) Vamos cuidar do Brasil: conceitos e práticas em educação ambiental. Brasília: MEC/UNESCO, 2007.

VEIGA, I. P. A. (org.). Projeto político pedagógico da escola: uma construção possível. Campinas: Papirus, 1995. p. 11-35.VEIGA, Projeto Político-Pedagógico da Escola: Uma Construção Possível. Campinas, SP: Papirus, 1995.

VEIGA, I.P.A. Inovações e projetos políticos-pedagógicos: uma relação regulatória ou emancipatória? Cad.Cedes, Campinas, v.23, n. 61, dez/2003. 